\title{
Multi-mycotoxins and Fungal Contaminants of Wheat from Anambra State, Nigeria
}

\author{
R.N. Amasiani' ${ }^{1}$, C.A Oyeka ${ }^{2}$ \\ 1 \& 2 Department of Applied Microbiology and Brewing, Faculty of Biosciences, Nnamdi Azikiwe \\ University, Awka, Nigeria
}

\author{
Article Info: Received 25 September 2021; Accepted 29 November 2021 \\ DOI: https://doi.org/10.32553/jbpr.v10i6.888 \\ Corresponding author: C.A Oyeka \\ Conflict of interest statement: No conflict of interest
}

\begin{abstract}
This study was carried out to determine the fungal and mycotoxins contamination of 36 Wheat (Triticum aestivium) samples purchased randomly from the seller of the agricultural produce in local markets of Anambra State, Nigeria. Results from the studies showed that two hundred and three fungal isolates consisting of 18 species of moulds and 5 species of yeasts contaminated the wheat samples at varying degrees. For moulds, Aspergillus species contaminated the samples mostly with (28) isolates followed by Penicillum species (19) isolates while Verticillium species and Cladosporium species had equal least contaminations with (3) isolates each. Among the yeast species, Candida rugosa had the highest number of contamination with (37) isolates followed by Cryptococcus laurentii (31) isolates while Candida stellatoides (9) isolates had the least contamination. Twenty-four fungal metabolites were also recovered. The concentration of trichothecene mycotoxin Deoxynivalenol $(2067 \mu \mathrm{g} / \mathrm{kg})$, a protein synthesis and cell proliferation inhibitor in animals exceeded the maximum acceptable limits for human consumption. It can be deduced therefore that wheat circulating in Anambra State, Nigeria are variously contaminated with different xerophilic moulds and mycotoxins which can exert adverse health problems to consumers.
\end{abstract}

Keyword: Wheat samples, fungal contaminants, multi-mycotoxins and market zones

\section{Introduction}

Wheat (Triticum spp)(order poales), is a cereal crop belonging to the family poaceae and is ranked as the third main staple food and industrial cash crop after maize and rice in Nigeria (Tanno and Willcox, 2006, Kolawole, et al., 2013). Wheat is widely cultivated in North Africa and in Sudan and Ethiopia and it is grown on around 10 million ha in Africa and it is also an imported commodity in all of Africa. African countries are the world's biggest wheat importer with more than $45 \mathrm{~m} \mathrm{t}$ in 2013 at around 15 billion US\$ Wheat imports account for $60 \%$ of African's wheat consumption and $80 \%$ of SubSaharan (SSA) countries (Macauley, 2015).

Wheat consumption is steadily increased in all African countries from the past 20 years as a result of growing population, changing food preferences and socioeconomic change associated with urbanization. In rapidly urbanizing in sub-Saharan Africa, wheat consumption is expected to grow to $38 \%$ by 2023 with imports already at $23 \mathrm{~m}$ tons of wheat 
in 2013 at a cost of $\$ 7.5$ billion. With the growing importance of wheat in food security in Africa, the African Union Heads of State in January 2013, endorsed to add wheat to the list of strategic crops for Africa (Macauley, 2015). Wheat grains are milled and are used to produce thick porridges and "swallows", which are known by various names in different parts of African continents (Ukwuru et al, 2018). Wheat is not widely grown in Nigeria and it serves as additional food or feed supplement that provides vegetable protein, minerals and vitamins to humans and livestocks (Kolawole et al, 2013). It is a major component of many other foods including breads, porridge, cracker and biscuits (Tanno and Willcox, 2006, Kolawole, et al., 2013).

However, the practices associated with production, processing and post processing handling of wheat, may exacerbate fungal contamination. Thus, the fungi contaminate the wheat samples on field, indeed accompany them to their storage points and may express the capacity to produce associated mycotoxins thus leading to a progressive deterioration in food quality, leading to alarming economic loss reflected as reduced productivity, discolouration, production of off-odours, direct commodity loss, livestock losses due to death and lower growth rates and human illness (Ogiehor and Ikenebomeh, 2006, Kolawole, et al., 2013). Mycotoxins are natural products (poison) produced by filamentous fungi which evoke toxic responses when introduced in low concentrations to higher vertebrates by natural routes (Oyeka, 2003). Mycotoxins are produced by fungi for a variety of reasons (1) to attack or gain access to hosts by helping to dissolve cell membranes. (2) As a protective measures against encroaching organisms (Zain, 2011). The occurrence of mycotoxins within the fungus and commodities depend on the particular crops, the environmental conditions under which a particular crop is grown, harvested, stored and or from the raw materials used in processing them which can be controlled. Other extrinsic factors like climate or intrinsic factors such as fungal strain, specifically strain variation, the particular enzymes of the fungus and instability of toxigenic properties which are more difficult to control (Zain, 2011). The fungi that produce mycotoxins do not have to be present to cause harm because they may be killed by heat (Oyeka, 2003) but the mycotoxins they produced on foods are stable under most food processing conditions and therefore, persist to the final products. It is therefore, difficult to eliminate them once the food stuffs are contaminated and usually there is no treatment for mycotoxin poisoning (Zain, 2011)

All mycotoxins are of fungal origin but not all toxic compounds produced by fungi are called mycotoxins. The target and the concentration of the metabolites are both important (Zain, 2011). Local food markets in developing countries like Nigeria are usually characterized by the absence of regulatory agencies and limited information on food quality; hence the constant selling of these fungal contaminated grains to consumers. Poverty, coupled with ignorance about mycotoxin contamination is also very important predisposing factors to consumers of contaminated food (Oyeka et al, 2019). Lack or absence of routine laboratory checks and diagnosis of mycotoxicosis has been complicated by a disregard on awareness of mycotoxin effects, acceptance of chronic low productivity and disease they cause. Also, lack of feed samples, sampling difficulties, analytical complications, species specific responses, nonspecific effects of mycotoxins on various body systems, universal symptoms that may be similar to other disorders and a cascading of animal responses (as seen with immune suppression) resulting in disorders not thought to be associated with mycotoxins hinder diagnosis of mycotoxins (CAST, 2003, whitlow and Hagler, 2005).

The survey for mycotoxigenic fungal contaminants of wheat consume in Anambra State, Nigeria would no doubt give an insight into the possible mycotoxins which can be produced in nature and their toxicological roles in human and animal health. 


\section{Materials and Methods:}

\section{Study Location:}

\section{Study Area}

This study was carried out in local markets of Anambra State. The local markets were divided into six zones viz: Zone 1- Aguata/Orumba North and South, Zone 2- Awka North /South, Zone 3- Nnewi North/South/Ihiala Ekwusigo, Zone 4- Ogbaru/Onitsha North/South, Zone 5Anaocha/. Idemili North/South, Zone 6Njikoka/Anyamelum/Oyi/Anambra East.

\section{Sample collection}

A total of thirty six (36) wheat samples ((Triticum aestivium) sample lots were purchased at random from six local market zones of Anambra State, Nigeria. The wheat samples were securely packaged in polythene bags, labeled properly and transported to the laboratory, stored under $4^{\circ} \mathrm{C}$ for later use for research analysis.

\section{Processing of samples}

The fungi were isolated using modified standard methods of Dubey and Maheshwari (2005). Duplicate samples of surface sterilized, blended, and serially diluted wheat samples were cultured in potato dextrose agar fortified with $0.5 \mathrm{mg} / \mathrm{ml}$ chloramphenicol. These were incubated for 5-7 days and regularly examined daily for fungal growth. The remaining portions of the wheat powder were stored for mycotoxins quantification Twenty (20) grams of twelve selected stored samples of ground wheat sample lots were chosen at random, packaged in zip lock paper envelopes, properly labeled and sent to Center for Analytical Chemistry, Department of Agro Biotechnology, University of Natural Resources and Life Sciences, Tulin, Austria for quantification of mycotoxins.

\section{Identification of isolates}

Identification of the isolates was based on extensive study of macroscopic and microscopic morphologies which was compared with standard texts of (Buhmer 1978; Frey et al 1979; De Hoog and Guarro 1995; Summerbell 1996;
David et al,2007). Moulds isolates were identified with Slide culture technique of (Errol et al 2012) while yeasts isolates were identified using Sugar fermentation tests of (Chessbrough 2004), urease test of (Mcginnis 1980), germ tube tests of (Chessbrough 2004), Corn meal ager test of (Acumedia 2011) and Chromogenic agar tests of (Massoud 2010).

\section{Chemicals and reagents}

Chemicals and reagents were obtained from Romer Labs Inc. (Tulln, Austria) and SigmaAldrich (Vienna, Austria). Standards of fungal metabolites were obtained from Iris Biotech GmbH (Marktred-Witz, Germany), Axxora Europe (Lausanne, Switzerland), and LGC (Promochem GmbH, Wesel, Germany).

Quantification of mycotoxin from wheat samples

Duplicate portions of the 12 randomly selected ground representative wheat samples were used for quantification of mycotoxins using Liquid chromatography tandem Mass Spectrometry (LC-MS/MS) method of (Malachova et al 2014). Five (5) grams of each representative samples were weighed into a $50-\mathrm{ml}$ polypropylene tube (Sarstedt, Nümbrecht, Germany) and $20 \mathrm{ml}$ of the extraction solvent (acetonitrile/water/acetic acid 79:20:1, v/v/v) added. Samples were extracted for 90 minutes on a GFL 3017 rotary shaker (GFL, Burgwedel,) and later diluted with the same volume of dilution solvent (acetonitrile/water/acetic acid $79: 20: 1, \mathrm{v} / \mathrm{v} / \mathrm{v}$ ) and subsequently centrifuged for 2 minutes at $3000 \mathrm{rpm}$ (radius $15 \mathrm{~cm}$ ) on a GS-6 centrifuge (Beckman Coulter Inc., Fullerton, CA). After appropriate mixing, 50 $\mu$ l of the diluted extracts were injected into the LCMS/MS system without further pre-treatment.

\section{Spiking of model matrices}

For spiking the model matrices, $0.25 \mathrm{~g}$ of a representative of the samples that were not contaminated with mycotoxins were weighed into $50 \mathrm{ml}$ of polypropylene tube. Multi - analyte standard in one concentration level was added in each of the tubes. The samples were placed in 
darkness to avoid analyte degradation and stored overnight at room temperature to allow evaporation of the solvent and to establish equilibrium between analytes and samples. The concentration range of the spiked samples were chosen to cover the respective limits of detection of each toxins, estimation linear calibration range, legislation limits of regulated toxins as well as the levels of commonly found toxins in naturally contaminated samples. External calibration was prepared by dilution of appropriate amounts of the final working solution with acetonitrile/water/acetic acid $(49.5 / 49.5 / 1, \mathrm{v} / \mathrm{v} / \mathrm{v})$ at level corresponding to those of the spiked samples. The corresponding peak areas of the spiked samples were used for the estimation of apparent recoveries by comparison to a multi-analytes standard on one concentration level prepared and diluted in neat solvent. All concentrations of the naturally contaminated samples were corrected by a factor equivalent to the reciprocal of apparent recovery (i.e $1 / \mathrm{R}_{\mathrm{A}}$, where $\mathrm{R}$ is the apparent recovery of each analyte) Malachova et al 2014.

$\mathbf{R}_{\mathbf{A}}=$ Average area of spiked samples x100

Average area (neat solvent standard)

\section{LC-MS/MS parameters}

Determination and quantification of target mycotoxins was performed with a QTrap 5500MS/MS system (Applied Biosystems, Foster City, CA) equipped with a TurboV electrospray ionization (ESI) source and a 1290 series HPLC system (Agilent Technologies, Waldbronn, Germany). Chromatographic separation was performed at $25^{\circ} \mathrm{C}$ on a Gemini ${ }^{\circledR C} 18$-column, $150 \times 4.6 \mathrm{~mm}$ i.d., $5 \mu \mathrm{m}$ particle size, equipped with a $\mathrm{C}_{18}$ security guard cartridge, $4 \times 3 \mathrm{~mm}$ i.d. (all from Phenomenex, Torrance, CA, US). ESI-MS/MS was performed in the time scheduled multiple reaction monitoring (MRM) mode both in positive and negative polarities in two separate chromatographic runs per samples by scanning two fragmentation reactions per analyte. The MRM detection window of each analyte was set to its expected retention time \pm 27 and \pm 48 in the positive and negative modes respectively. Confirmation of positive analyte identification of two MRMs per analyte (with the exception of Nitropropionic acid, which exhibited only one fragment ion) allowed confirming the identity of the positive results (Commission decision, 2002, Malachova et al 2014, Adetunji et al, 2014).

\section{STATISTICAL ANALYSIS}

The data collected were analysed with SPSS (Statistical Package for Social Sciences) version 21 (SPPS Inc., Chicago, IL, USA).

\section{Results}

A total of two hundred and three (203) fungal isolates were recovered from the study and Aspergillus species (28) had the highest number of moulds isolates followed by Penicillum species (19) isolates while the least Verticilium $s p$. and Cladosporium carrionii had 3 isolates each. In addition to moulds recovered, the study showed that yeasts were also very important fungal contaminants of the samples screened. Among the yeast species, Candida rugosa had the highest number of contamination with (37) isolates followed by Cryptococcus laurentii (31) isolates while Candida stellatoides had the least number of contamination with (9) isolates. Wheat from zone (1) had the highest fungal contamination with (76) isolates followed by those from zone (5) with (50) isolates while zone (2) had the least fungal contamination with (12) isolates. Statistical result showed that the frequency of moulds recovery was significant $\mathrm{P}$ $<0.05$, whereas the recovery of yeasts was not significant $\mathrm{P}>0.05$ (Table 1) 
Table 1: Fungi isolated from wheat samples in six market zones of Anambra State

\begin{tabular}{|l|l|l|l|l|l|l|l|}
\hline \multirow{2}{*}{ Isolated organisms } & \multicolumn{6}{|l}{ Market zones } \\
\cline { 2 - 8 } & $\mathbf{1}$ & $\mathbf{2}$ & $\mathbf{3}$ & $\mathbf{4}$ & $\mathbf{5}$ & $\mathbf{6}$ & frequency \\
\hline Aspergillus niger & 0 & 0 & 1 & 4 & 0 & 0 & $5(2.46 \%)$ \\
\hline Aspergillus flavus & 5 & 0 & 0 & 0 & 0 & 0 & $5(2.46 \%)$ \\
\hline Aspergillus fumigatus & 0 & 1 & 0 & 2 & 0 & 0 & $3(1.50 \%)$ \\
\hline Aspergillus versicolor & 0 & 5 & 0 & 0 & 0 & 0 & $5(2.46 \%)$ \\
\hline Aspergillus glaucus & 0 & 0 & 0 & 0 & 5 & 0 & $5(2.46 \%)$ \\
\hline Aspergillus terreus & 0 & 0 & 4 & 0 & 0 & 1 & $5(2.46 \%)$ \\
\hline & & & & Sub-total & & $\mathbf{2 8 ( 1 3 . 7 9 \% )}$ \\
\hline Penicillium cherasanum & 6 & 0 & 2 & 0 & 0 & 0 & $8(3.94 \%)$ \\
\hline Penicillium verrucosum & 5 & 0 & 0 & 0 & 3 & 0 & $8(3.94 \%)$ \\
\hline Penicillium marneffei & 0 & 0 & 3 & 0 & 0 & 0 & $3(1.50 \%)$ \\
\hline & & & & Sub-total & & $\mathbf{1 9 ( 9 . 3 6 \% )}$ \\
\hline Fusarium oxysporium & 0 & 0 & 0 & 3 & 3 & 2 & $8(3.94 \%)$ \\
\hline Fusarium solani & 1 & 0 & 1 & 2 & 0 & 0 & $4(1.97 \%)$ \\
\hline Fusarium aquaeductuum & 0 & 0 & 0 & 0 & 5 & 0 & $5(2.46 \%)$ \\
\hline & & & & \multicolumn{2}{|l|}{ Sub-total } & & $\mathbf{1 7 ( 8 . 3 7 \% )}$ \\
\hline Rhizopus oryzae & 0 & 0 & 0 & 2 & 0 & 3 & $5(2.46 \%)$ \\
\hline Verticillium sp. & 0 & 0 & 0 & 0 & 3 & 0 & $3(1.50 \%)$ \\
\hline Alternaria infectoria & 0 & 0 & 0 & 0 & 7 & 0 & $7(3.45 \%)$ \\
\hline Malbranchae sp. & 0 & 0 & 0 & 0 & 8 & 0 & $8(3.94 \%)$ \\
\hline Cladosporium carrionii & 0 & 3 & 0 & 0 & 0 & 0 & $3(1.50 \%)$ \\
\hline Trichoderma sp. & 4 & 0 & 0 & 0 & 0 & 0 & $4(1.97 \%)$ \\
\hline Cryptococcus laurentii & 5 & 3 & 2 & 0 & 16 & 5 & $31(15.27 \%)$ \\
\hline Candida stellatoides & 0 & 0 & 9 & 0 & 0 & 0 & $9(4.43 \%)$ \\
\hline Candida rugosa & 37 & 0 & 0 & 0 & 0 & 0 & $37(18.23 \%)$ \\
\hline Saccharomyces cerevisiae & 13 & 0 & 0 & 0 & 0 & 0 & $13(6.40 \%)$ \\
\hline Candida tropicalis & 0 & 0 & 0 & 0 & 0 & 19 & $19(9.36 \%)$ \\
\hline Total & $\mathbf{7 6}$ & $\mathbf{1 2}$ & $\mathbf{2 2}$ & $\mathbf{1 3}$ & $\mathbf{5 0}$ & $\mathbf{3 0}$ & $\mathbf{2 0 3 ( 1 0 0 \% )}$ \\
\hline
\end{tabular}

$P=0.021$ (Fungal isolationfrom grain samples were significant), $p=0.013$ (Moulds isolation was significant), $P=0.558$ (Yeast isolation not significant). 1 AON-Aguata/Orumba North \&South Market zone, 2- ANS-Awka North\& South market zone, 3 - NNSIE-NnewiNorth\&South/Ihiala/Ekwusigo market zone, 4 - OONS-Ogbaru/Onitsha North \&South market zone, 5 - AINS- Anaocha/Idemili North \&South market zone, 6 - NAOA Njikoka/Ayamelum/Oyi/Anambra East market zone.

Twenty-four fungal metabolites were recovered from the studied wheat samples with 14 Fusaria metabolites being the highly recovered followed by 5 Alternaria metabolites and 1 Penicillium metabolite as the least fungal meyabolite recovered. Analytical results of wheat samples showed high percentage recoveries (77.6-202.4\%) of fungal metabolites. The minimal quantification concentrations of fungal metabolites in the analyzed wheat samples ranged between $0.01 \mu \mathrm{g} / \mathrm{kg}$ (enniatin B3) and $409.8 \mu \mathrm{g} / \mathrm{kg}$ (Deoxynivalenol) (Table 2). 
Table 2: Table2: LC-MS/MS Method performance characteristics of Analytes in Wheat samples

\begin{tabular}{|c|c|c|c|c|c|}
\hline Metabolite category & Analyte & $\begin{array}{l}\text { Retention } \\
\text { time } \\
\text { (minute) }\end{array}$ & $\begin{array}{l}\text { Spiked } \\
\text { sample } \\
\text { LOD } \\
\mu \mathrm{g} / \mathrm{kg}\end{array}$ & $\begin{array}{l}\text { Net } \\
\text { standard } \\
\text { LOD } \\
\mu \mathrm{g} / \mathrm{kg}\end{array}$ & $\begin{array}{l}\text { Apparent } \\
\text { Recovery } \\
(\%)\end{array}$ \\
\hline Fusarium toxin & 15-hydroxyculmorin & 10.2 & 165.6 & 158.77 & 104.3 \\
\hline Aspergillus toxin & 3-Nitropropionic acid & 3 & 12.08 & 13.51 & 89.4 \\
\hline Alternaria toxin & Alternariol & 11 & 1.5048 & 1.56 & 96.5 \\
\hline Alternaria toxin & Alternariolmethylether & 12.8 & 0.7147 & 0.71 & 100.7 \\
\hline Aspergillus toxin & Asperglaucide & 11.6 & 14.896 & 14.9 & 100 \\
\hline Fusarium toxin & Beauvericin & 14.4 & 0.8296 & 0.86 & 96.5 \\
\hline Unspecific metabolite & Brevianamid F & 7.4 & 2.6384 & 2.64 & 100 \\
\hline Fusarium toxin & Culmorin & 12.2 & 23.8 & 22.45 & 106 \\
\hline Fusarium toxin & Deoxynivalenol & 5.8 & 409.8 & 382.95 & 107 \\
\hline Fusarium toxin & Deoxynivalenol-3-Glucoside & 5.6 & 19.704 & 19.66 & 100.2 \\
\hline Penicillium toxin & Emodin & 14.3 & 0.8136 & 1.06 & 81.4 \\
\hline Fusarium toxin & Enniatin A & 14.9 & 2.8168 & 2.78 & 101.3 \\
\hline Fusarium toxin & Enniatin A1 & 14.6 & 19 & 18.38 & 103.3 \\
\hline Fusarium toxin & Enniatin B & 14 & 22.432 & 22.8 & 98.4 \\
\hline Fusarium toxin & Enniatin B1 & 14.3 & 46.536 & 48.63 & 95.7 \\
\hline Fusarium toxin & Enniatin B2 & 13.7 & 1.2128 & 1.33 & 91 \\
\hline Fusarium toxin & Enniatin B3 & 13.2 & 0.01 & 0.01 & 100 \\
\hline Fusarium toxin & Equisetin & 15.1 & 0.8504 & 0.42 & 202.4 \\
\hline Alternaria toxin & Infectopyron & 9.4 & 329.04 & 329.04 & 100 \\
\hline Fusarium toxin & Nivalenol & 4.8 & 6.1744 & 7.96 & 77.6 \\
\hline Alternaria toxin & Tentoxin & 10.3 & 16.8 & 13.94 & 120.5 \\
\hline Alternaria toxin & Tenuazonic acid & 9.6 & 101.12 & 53.47 & 189.1 \\
\hline Unspecific metabolite & Tryptophol & 7.8 & 298.8 & 304.9 & 98 \\
\hline Fusarium toxin & Zearalenone & 11.9 & 5.6728 & 5.47 & 103.7 \\
\hline
\end{tabular}

LOD - limit of detection ( $\mathrm{S} / \mathrm{N}=3: 1)$ expressed in $\mu \mathrm{g} / \mathrm{kg}, \mathrm{RA}(\%)$-calculated from spiked experiment of a single wheat sample compared with the neat standard.

Quantification of metabolites

There was recoveries of regulated mycotoxins and non -regulated fungal metabolites from the analysed wheat samples; the regulated mycotoxins recovered include Deoxynivalenol and Zearalenone while the non-regulated fungal metabolites include 3-nitropropionic acid, alternariol, alternariol-methylether, asperglaucide, beavericin, deoxynivalenolglycoside, nivalenol, 15-hydroxyculmorin, , brevianamid F, culmorin, emodin, enniantin A, enniatin A1, enniatin B, enniatin B1, enniatin B2, enniatin B3, equisetin, infectopyron, tentoxin, tenuazonic acid, and tryptophol. The regulated mycotoxins recovered from the wheat samples had $100 \%$ contaminations while the non - regulated fungal metabolites recovered had moderate $(50-75 \%)$ to low $(33-42 \%)$ contamination ranges with the exception of nivalenol that had $100 \%$ contamination of the wheat samples analyzed (Table 3 
Table 3: Regulated and non-regulated microbial metabolites recovered in wheat samples.

\begin{tabular}{|c|c|c|c|c|c|c|c|c|c|c|c|c|c|c|}
\hline \multirow[t]{2}{*}{ Metabolites } & \multirow[t]{2}{*}{$\mathbf{n}^{\mathrm{c}}$} & \multirow[t]{2}{*}{$\begin{array}{l}\mathbf{p}^{\mathrm{c}} \\
(\%)\end{array}$} & \multicolumn{5}{|c|}{ Concentration $(\boldsymbol{\mu} / \mathbf{k g})$} & \multicolumn{7}{|c|}{$\begin{array}{l}\text { Proportion of contaminated wheat samples } \\
\text { across the six market zones }\end{array}$} \\
\hline & & & Min & Max & Median & Mean & SD & $\begin{array}{l}1 \\
(n=2)\end{array}$ & $\begin{array}{l}2 \\
(n=2)\end{array}$ & \begin{tabular}{l|l}
3 \\
$(n=2)$
\end{tabular} & & $\begin{array}{l}4 \\
(n=2)\end{array}$ & $\begin{array}{l}5 \\
(n=2)\end{array}$ & $\begin{array}{l}6 \\
(n=2)\end{array}$ \\
\hline \multicolumn{15}{|l|}{ Regulated mycotoxins } \\
\hline Deoxynivalenol $^{\mathrm{s}}$ & 12 & $\begin{array}{r}100 \\
12\end{array}$ & $\begin{array}{c}409.8 \\
100\end{array}$ & $\begin{array}{r}2067 \\
409\end{array}$ & $\begin{array}{|cc|}1030.7 \\
76 & 206 \\
\end{array}$ & 1100.2 & 1030.69 & 21100 & 2 & 639.8 & 2 & 2 & 2 & 2 \\
\hline Zearalenone $^{\mathrm{SS}}$ & 12 & 100 & \begin{tabular}{l|l}
5.67 \\
\end{tabular} & 7.82 & \begin{tabular}{|l|l}
6.75 \\
\end{tabular} & 6.56 & 0.79 & 2 & 2 & 2 & & 2 & 2 & 2 \\
\hline \multicolumn{15}{|l|}{ Non regulated } \\
\hline 3-Nitropropionic acid ${ }^{\mathrm{S}}$ & 7 & 58.3 & 12.08 & 14.29 & 12.62 & 12.91 & 0.89 & 1 & 1 & 1 & & 1 & 2 & 1 \\
\hline Alternariol $^{\mathrm{SS}}$ & 6 & 50 & 1.5 & 18.33 & 13.7 & 12.44 & 5.71 & 1 & 0 & 2 & & 1 & 1 & 1 \\
\hline Alternariol- methylether ${ }^{\text {SS }}$ & 5 & 41.7 & 0.71 & 0.92 & 0.71 & 0.78 & 0.1 & 1 & 1 & 1 & & 0 & 2 & 0 \\
\hline Asperglaucide $^{\mathrm{SS}}$ & 7 & 58.3 & 14.9 & 22.53 & 18.78 & 18.19 & 3.42 & 1 & 2 & 2 & & 0 & 1 & 1 \\
\hline Beavericin $^{\text {SS }}$ & 8 & 66.7 & 0.83 & 0.96 & 0.87 & 0.88 & 0.05 & 2 & 2 & 2 & & 1 & 1 & 0 \\
\hline Deoxynivalenol glycoside & 8 & 66.7 & 19.7 & 33.9 & 23.6 & 25.65 & 6.58 & 2 & 2 & 2 & & 1 & 1 & 0 \\
\hline Nivalenol $^{\mathrm{SS}}$ & 12 & 100 & 6.17 & 10.9 & 8.07 & 8.22 & 1.84 & 2 & 2 & 2 & & 2 & 2 & 2 \\
\hline 15-hydroxyculmorin ${ }^{\mathrm{s}}$ & 8 & 67 & 165.6 & 268 & 182.06 & 203.5 & 43.53 & 2 & 1 & 2 & & 1 & 1 & 1 \\
\hline Brevianamid $\mathrm{F}^{\mathrm{s}}$ & 12 & 100 & 2.64 & 2.7 & 2.67 & 2.67 & 0.3 & 2 & 2 & 2 & & 1 & 2 & 1 \\
\hline Culmorin & 7 & 58 & 23.8 & 25.4 & 23.9 & 24.08 & 1.14 & 1 & 2 & 2 & & 1 & 1 & 0 \\
\hline Emodin $^{\mathrm{s}}$ & 9 & 75 & 0.8 & 1.8 & 0.81 & 1.04 & 0.42 & 1 & 2 & 2 & & 1 & 2 & 1 \\
\hline Enniatin $A^{s s}$ & 8 & 67 & 2.82 & 4.76 & 2.82 & 3.2 & 0.7 & 2 & 2 & 2 & & 1 & 1 & 0 \\
\hline Enniatin $\mathrm{A} 1^{\mathrm{s}}$ & 7 & 58 & 19 & 33.6 & 25.72 & 26.16 & 5.42 & 2 & 2 & 1 & & 1 & 0 & 1 \\
\hline Enniatin $\mathrm{B}^{\mathrm{s}}$ & 5 & 42 & 22.43 & 50.8 & 31.97 & 36.04 & 12.94 & 1 & 1 & 1 & & 0 & 2 & 0 \\
\hline Enniatin $\mathrm{B} 1^{\mathrm{s}}$ & 4 & 33 & 46.54 & 80.2 & 46.55 & 54.02 & 14.81 & 1 & 1 & 1 & & 1 & 0 & 0 \\
\hline Enniatin B2 ${ }^{\mathrm{s}}$ & 6 & 50 & 1.21 & 1.66 & 1.2 & 1.23 & 0.6 & 2 & 1 & 1 & & 0 & 2 & 0 \\
\hline Enniatin $\mathrm{B} 3^{\mathrm{s}}$ & 5 & 42 & 0.01 & 0.04 & 0.01 & 0.02 & 0.01 & 1 & 1 & 1 & & 0 & 1 & 1 \\
\hline Equisetin $^{\text {ss }}$ & 5 & 42 & 0.85 & 2.4 & 0.87 & 1.36 & 0.72 & 1 & 1 & 1 & & 1 & 1 & 0 \\
\hline Infectpyron $^{\text {ss }}$ & 6 & 50 & 329 & 364.6 & 343.51 & 343.95 & 14.36 & 2 & 1 & 2 & & 0 & 0 & 1 \\
\hline Tentoxin ${ }^{\mathrm{ss}}$ & 8 & 67 & 16.8 & 29.6 & 24.2 & 23.3 & 5.6 & 2 & 1 & 2 & & 1 & 2 & 0 \\
\hline Tenuazonic acid & 8 & 67 & 101.1 & 264.7 & 201.1 & 190.9 & 64.9 & 2 & 2 & 1 & & 1 & 1 & 1 \\
\hline Tryptophols & 5 & 42 & 298.8 & 316.5 & 305.9 & 306.7 & 7.7 & 1 & 1 & 1 & & 0 & 1 & 1 \\
\hline
\end{tabular}

$\mathrm{n}=$ number of samples examined

$\mathrm{n}^{\mathrm{c}}$ number of samples contaminated

${ }^{c}$-percentage of contaminated samples

$<$ LOD - less level of detection

Market zones: 1 (Aguata/Orumba North ans south), 2 (Awka north and south), 3(Nnewi north/south Ihiala/Ekwusigo,

4 (Ogbaru/ Onitsha north/south, 5 (Anaocha/Idemili north/south) 6 (Njikoka/Ayamelum/Oyi/Anambra East

The superscript ${ }^{\mathrm{s}}$ indicates mycotoxins with significant differences $(\mathrm{P} \leq 0.05)$ among wheat samples screened

The superscript ${ }^{\text {ss }}$ indicates mycotoxins with significant differences $(\mathrm{P} \leq 0.05)$ among wheat samples and market zones

\section{Discussions}

The genus Aspergillus dominated other mould species recovered from wheat samples in this study; this was followed by Penicillium, Fusarium, Malbranchae, Alternaria, Rhizopus, Trichoderma, Cladosporium and Verticillium. Many factors in field conditions and during storage act together in the contamination of crops and production of mycotoxins by these fungi, (Enyiukwu et al, 2014). Important mycotoxins producing fungi belonging to the genus Aspergillus, Penicillium, Fusarium and Alternaria are the major contributor of food contamination. Elaaraj et al (2015) reported Aspergillus as the most predominantly isolated fungal organisms in wheat samples followed by Penicillium, Fusarium, Alternaria and Cladosporium. Some of the mould species obtained in this study from wheat samples belong to genera they isolated. The fungi 
isolated from the six market zones of Anambra State showed that wheat bought from market zone 1 had the highest fungal isolates (76), followed by those form zone 5 (50) isolates while the least was from market zones 2 (12 isolates) (Table 1). Yeasts also implicated as contaminants of the samples metabolize some food components and produce metabolites which cause the physical, chemical, and sensible properties of a food to change and thus food spoilage (Fleet and Praphailong 2001) though they do not produce mycotoxins. Saccharomyces cerevisiae is common food and environmental saprophyte and was isolated in this study, Candida tropicalis is found as part of the normal human mucocutaneous flora, its environmental isolations may be that the samples were contaminated with faeces, and contaminated soil (David et al, 2007). Candida tropicalis and Saccharomyces cerevisiae were recovered by Desiye and Abegas, 2013 from teff batter (Ethiopian pancake). Environmental isolations of Candida Stellatoides and Candida.rugosa may be that the sources of the samples are contaminated by human or animal excreta, polluted water, soil, air and plants. Candida rugosa has been associated with catheter related fungemia, (David et al, 2007). Wheat samples sold in Anambra State local markets were unique; rare mycotoxins were recovered from the samples. The conventional mycotoxins (Aflatoxins, Ochratoxins and Fumnosins) were not recovered in the study. This may be because wheat are not produced in Anambra State but are bought from the northern part of the country and they are usually stored for short period in bags in the market places by the traders thus limiting the conditions that favour the mycotoxigenic fungi that produce Aflatoxins, Fumnosin and Ochratoxins (Oyeka et al, 2019).

Anambra State is in the rain forest zone with high rain fall pattern about (1300 - 2000mm), suitable temperature and high relative humidity which favours the growth of mycotoxigenic fungi (Udo et al, 2000, Oyeka, et al 2019). Fusarium fungal metabolites dominated other fungal metabolites recovered in this study. Fusaruim being field fungi may have contaminated the samples in the field and accompanied the samples to the storage and market places. The short storage of the samples by the traders gave room to Fusarium fungal metabolites to dominate the storage fungal metabolites of Penicillium sp and Aspergillus sp) Oyeka et al, 2019).

Zearalenone, deoxynivalenol and nivalenol had $100 \%$ contamination of all the wheat samples. The concentration of regulated mycotoxin deoxynivalenol $(409.8-2067 \mu \mathrm{g} / \mathrm{kg})$ in the studied samples exceeded maximum acceptable limits (MAL) for human consumption (European Commission (EC, 2006). Deoxynivalenol is a trichothecene; immunosuppressive and protein synthesis inhibitor in animals and humans (CAST, 2003). Deoxynivalenol glycoside; a masked form of deoxynivalenol contaminated the samples with concentration range of (19.7- $33.9 \mu \mathrm{g} / \mathrm{kg})$. Regular consumption of wheat containing low levels of deoxynivalenol and its masked form toxin may lead to acute toxicity to human and animals. Nivalenol, another type B immunosuppressive, protein inhibitor trichothecene and a non- regulated fungal metabolite contaminated the samples with concentration range of $(6.2-10.9 \mu \mathrm{g} / \mathrm{kg})$ and mean level of $(8.22 \mu \mathrm{g} / \mathrm{kg})$ respectively. The metabolite nivalenol, is as toxicity as deoxynivalenol, therefore, any synergistic reaction of nivalenol and deoxynivalenol recovered in this study in animals will be a public health risk significance Oyeka et al, 2019 ..

The oestrogeniuos mycotoxin zearalenone implicated in alterations in humans and animals reproductive tract, decrease in fertility or infertility, increase in number of foetal resorptions and implantation failure, reduced litter size, permanent damage to reproductive tracts, human cervical cancer, and outbreaks of precocious pubertal changes in children among other problems (CAST, 2003, Oyeka, 2003) contaminated the samples with the 
concentrations $(5.7-7.8 \mu \mathrm{g} / \mathrm{kg})$ which are within the acceptable limits of human consumption (European Commission (EC, 2006).

Enniatins (A, A1, B, B1, B2, and B3) are similar to Beavericin in function and toxicity. Enniatins (A, A1, B, B1, B2, and B3 and Beauvericin are mixtures of isomeric and homologous cyclodepsipeptides (Taylor, 1970). Enniatins were thought to be similar but are chemically distinct antibiotics. They are mixtures of isomeric and homologous cyclodepsipeptides to which the general name "enniatin" is applied. Enniatins are powerfully bioactive, apparently by interaction with membrane components, these properties they shared to some extent by the related cyclo-octadepsipeptide- valinomycin but there are differences, notably with regard to ion-selectivity (Audhya and Russel (1974). Beauvericin contaminates cereals and is genotoxic and can induce apoptosis in several human cells including lymphocytes (Adetunji et al, 2014), Oyeka et al, 2019. Considering the percentage contamination and different concentrations of these seven fungal metabolites in the studied wheat samples, they may be toxic to human and animal especially the Beauvericin (66.7\%), Enniatin A (67\%) and Enniatin BI which recorded higher concentration range of 46 $.54-80.2 \mu \mathrm{g} / \mathrm{kg}$.

Postulation has been made on Equisetin on its possible role in human leukomogen and also a strong antibiotic to certain Gram positive bacterial. It is phytotoxic to plants and inhibits growth of various dicotyledonous and monocotyledonous plants. Roots, shoots and coleoptiles growth of these plants is usually inhibited by the microbial metabolite, at concentration of $10 \mu \mathrm{g} / \mathrm{kg}$ for $72 \mathrm{hrs}$, thus permanently damage the plants seedlings though the concentrations $(2.4 \mu \mathrm{g} / \mathrm{kg})$ recorded in this study were below $10 \mu \mathrm{g} / \mathrm{kg}$ (Wheeler et al, 1999). Much have not been documented about the effects of the microbial metabolites in human but they may work in synergy with other known Fusarium mycotoxins to cause harm to human and animals when continuous consumption of contaminated wheat with the Fusarium metabolites and other known Fusarium toxins take place Oyeka et al, 2019.

Penicillium metabolites Emodin has antibiotic property and had $75 \%$ contamination of the samples. Emodin has been reported to be toxic to cells (Ezekiel et al, 2012).

Alternaria metabolites, Infectopyron, Tentoxin and Tenuazonic acid had moderate percentage occurrence in the samples. Concentration of Tenuazonic acid $(101.1-265 \mu \mathrm{g} / \mathrm{kg}$, median $=$ $201.1 \mu \mathrm{g} / \mathrm{kg}$ ) in the wheat samples studied was higher than what was reported in rye flour $(57 \mu \mathrm{g} / \mathrm{kg})$ in Germany by Asam et al, 2012. The co-presence of Alternariol, Alternariolmethylether, Tentoxin with Tenuazonic acid further confirms the infestation of the samples by Alternaria fungal species. From toxicological stand point, Tenuazonic acid is known to be toxic to chick embryo and some animal species inducing haemorrages in vital organs principally through the inhibition of protein synthesis by suppression of the release of newly formed proteins from the ribosomes into the supernatant fluid, (Ezekiel et al, 2012). Acute toxicosis by Tenuazonic acid may pose a threat to consumers though chronic exposure of the toxin has not yet been investigated; toxic situations may be more complicated due to synergism by many metabolite combinations (Ezekiel et al, 2012).

Brevianamid $F$ and Tryptophol fungal metabolites of many species of fungi also contaminated the samples with $100 \%$ and $42 \%$ contamination respectively. Much has not been known about the toxicity of these two metabolites in human and animals. Ezekiel et al, 2012 reported $100 \%$ contamination of all the fonio and sesame samples by these unspecific fungal metabolites. Misihairdgwi et al. (2019) also found brevianamid (100\%) and tryptophol (74\%) in vegetables in Namibia. Oyeka et al, 2019 recovered these unspecific fungal metabolites (Brevianamid F $(100 \%)$ and Tryptophol (70\%) in maize in Anambra State, Nigeria.

\section{Conclusion}


The co-presence of mycotoxigenic fungi, the studied mycotoxins and other fungal metabolites in the samples as demonstrated in this study implies that the samples could contain fungal toxins that can cause human and animal mycotoxicosis. The concentration of the immunosuppressive deoxynivalenol (409.8 $2067 \mu \mathrm{g} / \mathrm{kg}$ ) above the acceptable limit of human consumption in this study is a source of worry. Therefore, the consumption of the contaminated samples could have adverse consequences on national livestock production, human and economy.

\section{Acknowledgments}

We give our profound gratitude to Prof. Olusegun Atanda of Mcpherson University, Abeokuta, Ogun State, Nigeria and Mr. Duru Samuel Ngozi of Nigerian Stored Products Research, Institute Port Harcourt, Rivers State, Nigeria who gave the contact for quantification of mycotoxins. We are also thankful to Dr. Michael Sulyok and Prof. Rudolf Kraska of Centre for Analytical Chemistry, Department of Agro biotechnology, University of Natural Resources and Life Sciences, Tulln, Austria who agreed to carry out the mycotoxin quantification analysis of our samples.

\section{Disclosure statement}

The authors alone are responsible for the content and writing of this manuscript. Therefore, there is no potential conflict of interest by the authors.

\section{References}

1. Acumedia (2011). Corn meal agar (7350). Neogen Cooperation, 620 lesher place, Lansing, Michigan, United States. [Assessed 2017 May 5]. www.neogen.com.

2. Adetunji M, Atanda O, Chibundu NE, Michael S, Benedikt W, Eduardo B, Rudolf K. 2014. Fungal and bacterial metabolites of stored maize (Zea mays, L.) from five agroecological zones of Nigeria. Mycotox Res. 30(2):89-102. doi:10.1007/ s12550014-0194-2.

3. Asam, S., Lichtenegger M., Liu Y. and Rychlik, M (2012). Contents of the
Alternaria mycotoxin Tenuazonic acid in food commodities determined by a stable isotope dilution assay. Mycotoxins Research, 28:9-15.

4. Audhya, T. K. and RusselL, D. W. (1974). Production of Enniatins by Fusarium sambucinum: Selection of High=yield Conditions from Liquid Surface Cultures. Journal of General Microbiology, 82, 181190

5. Bulmer, G. S. (1978). Color Atlas of Medical Mycology. Upjohn company, Kalamazoo, Michigan.

6. CAST (Council for Agricultural Science and Technology) (2003). Mycotoxins; risk in plants and animal systems. Task Force Report No. 38 Council for Agricultural Science and Technology, Aries, Iowa (USA). Pp 1-199.

7. Chessbrough M. 2004. District laboratory practice in tropical countries. Cambridge University Press, The Edinburgh Building, Cambridge CB2 8RU, United Kingdom; p. 401-402.

8. Commission decision (2002) Implementing Council Directive 96/23/EC concerning the performance of analytical methods and the interpretation of results $(2002 / 657 / \mathrm{EC})$, [Assessed 2016 Aug 6], http://eurlex.europa.eu/LexUriServ/LexUri Serv.do/uri=OJ:L:2002:221:0008:0036:EN: PDF

9. David E, Steven D, Alexiou H, Handke R, Bartley R (2007). Description of medical fungi. Published by the Authors Mycology Unit Women's and Children's Hospital. School of molecular and biomedical science University of Adelaide, Adelaide, Australia. Pp. 1-197.

10. De Hoog GS, Guairo J, Tan CS. 1995. Atlas of clinical fungi. Spain: University Rovira I virgilli Reus; p. 1-78.

11. Desiye, A and Abegaz, A. (2013). Isolation, characterization and identification of lactic acid bacteria and yeast involved in fermentation of Teff (EragrostisTef) Batter. Access International Journals, 1(3):36-44. 
12. Dubey RC, Maheshwari DK. 2005. Practical mycology. New Delhi (India): S Chaud and Company.

13. Elaaraj, C., Bakkali, M,. Arakrak, A. and Laglaout, A. (2015). Mycotoxigenic Fungi in Cereals grains and coffee from the North of Morocco. American Journal of Research Communication, 3(2).130-142.

14. Enyiukwu, D. N., Awurum, A. N. and Nwaneri, J.A. (2014). Mycotoxins in Stored Agricultural Products: Implications to Food Safety and Health and Prospects of Plantderived Pesticides as Novel Approach to their Management. Greener Journal of Microbiology and Antimicrobials, 2 (3): 032-048.

15. Errol R, Jean HS, Marshall G. 2012. Fundamentals of medical mycology. Hoboken (New Jersey): Wiley-Blackwell Publication; p. 47-48.

16. European Commision, 2006. Commission regulation 2006/ 1881/EC of 19 December 2006 replacing regulation (EC) 466/2001 setting maximum levels for certain contaminants in foodstuffs. OJ L 364/5-24, 20.12.2006.

17. Ezeikiel,. C. N., Sulyolk,.M. Warth,. B. and Kraska,. R. (2012). Multi-microbial metabolites in fonio millet (acha) and sesame seeds in Plateau State, Nigeria. Journal of European Food Resources and Technolog, 235:285-293.

18. Fleet, G. H. and Praphailong, W. (2001). "Yeasts". In: Moir, C. J. (ed). Spoilage of Processed Foods: Causes and Diagnosis. Food Microbiology Group of the Australian Institute of Food Science and Technology (AIFST). pp. 383-397.

19. Frey, D., Oldfield, R. J. and Bridger, R. C. (1979). A Colour Atlas of Pathogenic Fungi. Wolfe medical Publications Ltd. Pp 49-106.

20. Kolawole, R, M., Thomas, R.T, Adekunle, A.A. and Oluwadun, A. (2013). Postharvest Pathogenic Fungi of wheat circulating in Lagos State, Nigeria. American Journal of Research Communication. Vol 1(12). Pg 421-428.
21. Macauley, .H.(2015).Cereal Crops: Rice, Maize, Millet, Sorghum, Wheat Feeding Africa: An action plan for African Agricultural Transformation. Abdou Dioul International conference Center, Dakar, Senegal. Pps 1-31. https://www.afdb.org/fileadmin/uploads/afd b/Documents/Events/DakAgri2015/Cereal_ Crops-

Rice Maize Millet Sorghum Wheat .pdf Accessed 9th June, 2020.

22. Malachova A, Sulyok M, Beltran E, Berthillere F, Krska R. 2014. Optimization and validation of a quantitative liquid chromatography- tandem mass spectrometric method covering 295 bacterial and fungal metabolites including all regulated mycotoxins in four model food matrices. Journal of Chromatograph. 1362:145-156.

23. Massoud V (2010). Conda news. Facts about micro and molecular biology. An article on Chromogenic media. Pp. 1-2.

24. McGinnis MR. 1980. Laboratory handbook of medical mycology. New York (United States): Academic press; p. 175-177, 274 276.

25. Misihairdgwi JM, Ishola A, Sulyok M, Krska R. 2019. Mycotoxin and cyanogenic glycoside assessment of traditional leafy vegetables mutate and omboga from Namibia. Food Addit \& Contam: Part B. doi:10.1080/19393210.1616829.

26. Ogeihor JS, Ikenebomeh MJ (2006). The effect of different packaging materials on the shelf life of garri. African Journal of Biotechnology, 523: 2412-2416.

27. Oyeka, C. A, Amasiani, R. N. \& Ekwealor, C.C. (2019). Mycotoxins contamination of maize in Anambra State, Nigeria. Journal of Food Additives \& Contaminants: Part B. pgs 1-9.

28. Oyeka, C. A. (2003). Mycotoxins in human and animal health. New generation books, Nigeria. Pp 1-30.

29. Summerbell, R. (1996). A Clinical laboratory handbook. Star Publishing 
Company, Belmont, Califonia USA. Pp 1237.

30. Tanno K and Willcox G (2006). How fast was wild wheat domesticated? Science, 311:77-80.

31. Taylor, A. (I970). The occurrence, chemistry, and toxicology of the microbial peptide-lactones. Advances in Applied Microbiology, 12: I89-276.

32. Udoh J.M, Cardwel KF, Ikotun T. 2000. Storage structures and aflatoxin content of maize in five agroecological zones of Nigeria. J Stored Prod Res. 36:187-201. doi:10.1016/S0022- 474X(99)00042-9.

33. Ukwuru, M.U, Muritala, A. and Iheofor, A.O. (2018). Cereal Utilization in Nigeria.
Research Journal of Food and Nutrition Volume 2, Issue 3, 2018, PP 1-12.

34. Wheeler, M.H., Stipanovic, R. D. and Puckhaber, L.S. (1999). Phytotoxicity of equisetin and epi-equisetin isolated from Fusarium equiseti and $F$. pallidoroseum. Mycological Research, 103 (8): 967-973.

35. Whitlow, L. W and Hagler, W. M (2005). Mycotoxins in dairy cattle; Occurrence, toxicity, Prevention and treatment. Proceedings southwest nutrition conference. Pp 124-130

36. Zain, M, E. (2011). Impact of mycotoxins on human and animals. Journal of chemical society, 15 (2): 129-144. 